\title{
Imported Canine leishmaniasis in Romania: a Case Report
}

Gina Corina TOMA ${ }^{1}$, Marian TAULESCU ${ }^{1}$, Viorica MIRCEAN ${ }^{2}$, Angela Monica IONICÄ ${ }^{2}$, Roxana CORA ${ }^{1}$, Cornel CĂTOI ${ }^{1}$, Mirabela Oana DUMITRACHE ${ }^{2, *}$

${ }^{1}$ Department of Pathology, Faculty of Veterinary Medicine, University of Agricultural Science and Veterinary Medicine, Cluj-Napoca

${ }^{2}$ Department of Parasitology and Parasitic Diseases, University of Agricultural Sciences and Veterinary

Medicine, Romania

*corresponding author: mirabela.dumitrache@usamvcluj.ro

Bulletin UASVM Veterinary Medicine 75(1)/2018

Print ISSN 1843-5270; Electronic ISSN 1843-5378

doi:10.15835/buasvmcn-vm:002317

\begin{abstract}
Canine leishmaniasis (CanL) is a zoonotic disease considered endemic in the Mediterranean region. Romania is traditionally regarded as a non-endemic country.

Considering the zoonotic character of the disease, this study aims to increase the knowledge on diagnostic aspects of CanL.

A 2-year-old, mix breed male dog, recently returned from Italy had a history of progressive weight loss and skin lesions. The clinical examination was followed by hematology and serum biochemistry, fine-needle aspiration of lymph nodes, impression smears, VetExpert ${ }^{\circledR}$ rapid test Leishmania Ab, and PCR. The clinical examination revealed muscle atrophy, non-pruritic crusting dermatitis, ulcers, and lymphadenopathy. Hematology showed severe anemia. The serum biochemistry revealed hyperproteinaemia, hypoalbuminemia, hyperglobulinemia. Cytological exams evidenced the intracellular amastigotes in macrophages, confirmed by rapid test and PCR.

In Romania, under the light of the new case reports, leishmaniasis should be reconsidered from both veterinary and public health perspective.
\end{abstract}

Keywords: dog, leishmaniasis, imported, Romania

\section{Introduction}

Canine leishmaniasis (CanL) is zoonotic vector-borne disease produced by Leishmania infantum (Otranto and Dantas-Torres, 2013), a protozoan parasite transmitted by the bite of infected female sand flies of genus Phlebotomus (Maroli et al., 2013, Otranto and Dantas-Torres, 2013). Dogs are considered the main peridomestic reservoirs of $L$. infantum. In Europe, leishmaniasis is considered an endemic zoonotic disease in the Mediterranean region (Maia, Cardoso, 2015). By now, about 700 imported CanL were reported from non-endemic countries of Europe (Antoniou et al., 2013, Maia, Cardoso, 2015). Currently, leishmaniasis has a tendency of expanding in areas of north-western Italy with continental climate, far from the recognized regions of Mediterranean coasts (Ferroglio et al., 2005). Global warming can be incriminated as a cause of spread of the disease to areas where it was not reported before (Desjeux, 2001).

According to The World Health Organization (WHO), the risk of leishmaniasis in humans has been underestimated worldwide (WHO, 2009, Ready, 2010). Romania is traditionally regarded as a country with low risk of leishmaniasis and human cases were detected sporadically (Ready, 2010). The first case of autochthonous human leishmaniasis in Romania was described in 1912. Between 1944 and 1955, 26 additional autochthonous cases have been reported, all originating from southern Romania. The first 
report of clinical autochthonous CanL was in 1935. Between 1969 and 2013 no autochthonous cases of human or canine leishmaniasis were reported, and all diagnosed infections were imported (Dumitrache et al., 2016). In 2013, more than 80 years after the first case of autochthonous visceral leishmaniasis, an autochthonous human case was reported and just one year later, an autochthonous clinical case of CanL was described (Mircean et al., 2014). Recent epidemiological studies showed a molecular and serological prevalence of $8.7 \%$ in dogs from Râmnicu Vâlcea (Gogoaşe et al., 2013, Dumitrache et al., 2016), the geographical location of the canine case. All positive dogs were asymptomatic. There are no recent studies of sand fly distribution in Romania (Dumitrache et al., 2016).

\section{Materials and methods}

A 2 years-old, mixed-breed male dog was referred to a private practice in Cluj-Napoca (Romania) due to skin disorders, progressive weight loss and inappetence, in the past 6 months. The dog was born in Italy and lived in Florence area and it recently came to Romania. A complete clinical examination was followed by serum biochemistry and hematology. A cytological exam was performed by fine needle aspiration (21G) from popliteal and mandibular lymph nodes and impression smears of the internal parts of crusts, stained Diff-Quick. To verify one of the hypothetical diagnosis, a chromatographic immunoassay qualitative test (VetExpert ${ }^{\circledR}$ rapid test Leishmania $\mathrm{Ab}$ ) was used. Conjunctive swabs were collected for real-time PCR, targeting the kinetoplast minicircle DNA from L. infantum. Genomic DNA was extracted using a commercial kit (Isolate II Genomic DNA Kit, Bioline, London, UK). The primers used were LEISH-1 and LEISH-2, previously described by Francino et al., 2006.

\section{Results and discussions}

Clinical examination of the dog showed muscle atrophy, emaciation, mucous membrane pallor, exercise intolerance and generalized peripheral lymphadenopathy, bilateral conjunctivitis, nonpruritic exfoliative dermatitis with abundant grey scales involving ears pinnae, periorbital area and muzzle (Fig. 1A, 1B). The lesions were presenting marked bilateral symmetry. Other skin lesions were affecting the limbs and were represented by atonal multifocal skin ulcers, fissured footpads and onychogryphosis (Fig. 1C).

Serum biochemistry revealed hyperproteinaemia $7.49 \mathrm{~g} / \mathrm{dL}$ [reference range $4.2-5.2 \mathrm{~g} /$ $\mathrm{dL}$ ], hyperglobulinemia $3.5 \mathrm{~g} / \mathrm{dL}$ [0.42-0.88], hypoalbuminemia $1.89 \mathrm{~g} / \mathrm{dL}$ [1.98-2.9 g/dL] and a moderate increase in gamma-glutamyltransferase levels $10.97 \mathrm{U} / \mathrm{L}$ [<10 U/L]. Urea, creatinine, alanine aminotransferase (ALAT) and aspartate aminotransferase (ASAT) were within normal ranges. The complete blood count revealed a severe anemia (RBC 2.98 $\times 10^{6} / \mathrm{mm}^{3}\left[5.5-8.53 .29 \times 10^{6} / \mathrm{mm}^{3}\right]$, hemoglobin $7.1 \mathrm{~g} / \mathrm{dL}$ [15-20 g/dL], hematocrit $20.2 \%$ ) with a positive autoagglutinaton test. Hematology also revealed leukocytosis $17.5 \times 10^{3} /$ $\mathrm{mm}^{3}\left[6-12 \times 10^{3} / \mathrm{mm}^{3}\right]$ with monocytosis $1.1 \times 10^{3} /$ $\mathrm{mm}^{3}\left[0-0.5 \times 10^{3} / \mathrm{mm}^{3}\right]$ and granulocytosis 14.4 $\mathrm{x} 10^{3} / \mathrm{mm}^{3}\left[3-10 \times 10^{3} / \mathrm{mm}^{3}\right]$.

The cytology of the internal part of the crusts revealed a high number of neutrophils and hypertrophic macrophages. Few of the macrophages possessed a small number of intracellular organisms (amastigotes) measuring 1.5-2 x 2.5-5 $\mu \mathrm{m}$ with a large nucleus a distinct kinetoplast (Fig. 1D). The kinetoplasts were perpendicular or parallel to the nucleus.

Cytology of lymph nodes aspirates evidenced a mixed lymphoid population (predominately small lymphocytes and increased number of medium and large lymphocytes) compatible with a reactive lymph node (Fig. 1E)., numerous plasma cells and rare macrophages (lymphoplasmacytic inflammation) The parasite was identified also in thelymph nodeaspirates as rareintracytoplasmatic organisms, in macrophages.

Due to the zoonotic aspects and the severity of the clinical signs, in the current case, euthanasia was recommended.

The main reservoir of Leishmania infantum is considered the dog, due to the proximity of these animals to humans (Ready, 2010). Nowadays, the travelling of companion animals, including dogs, together with their owner, is facilitated by minimum requirements at the borders (agreed by most of the countries). Mainly, a dog must own a passport and it must be microchipped, vaccinated against rabies, dewormed and treated against fleas and ticks, with 24-48 h prior to cross the border). There are no restrictions regarding the active substances used for ticks and flea treatments. The transport of the companion animals could be 

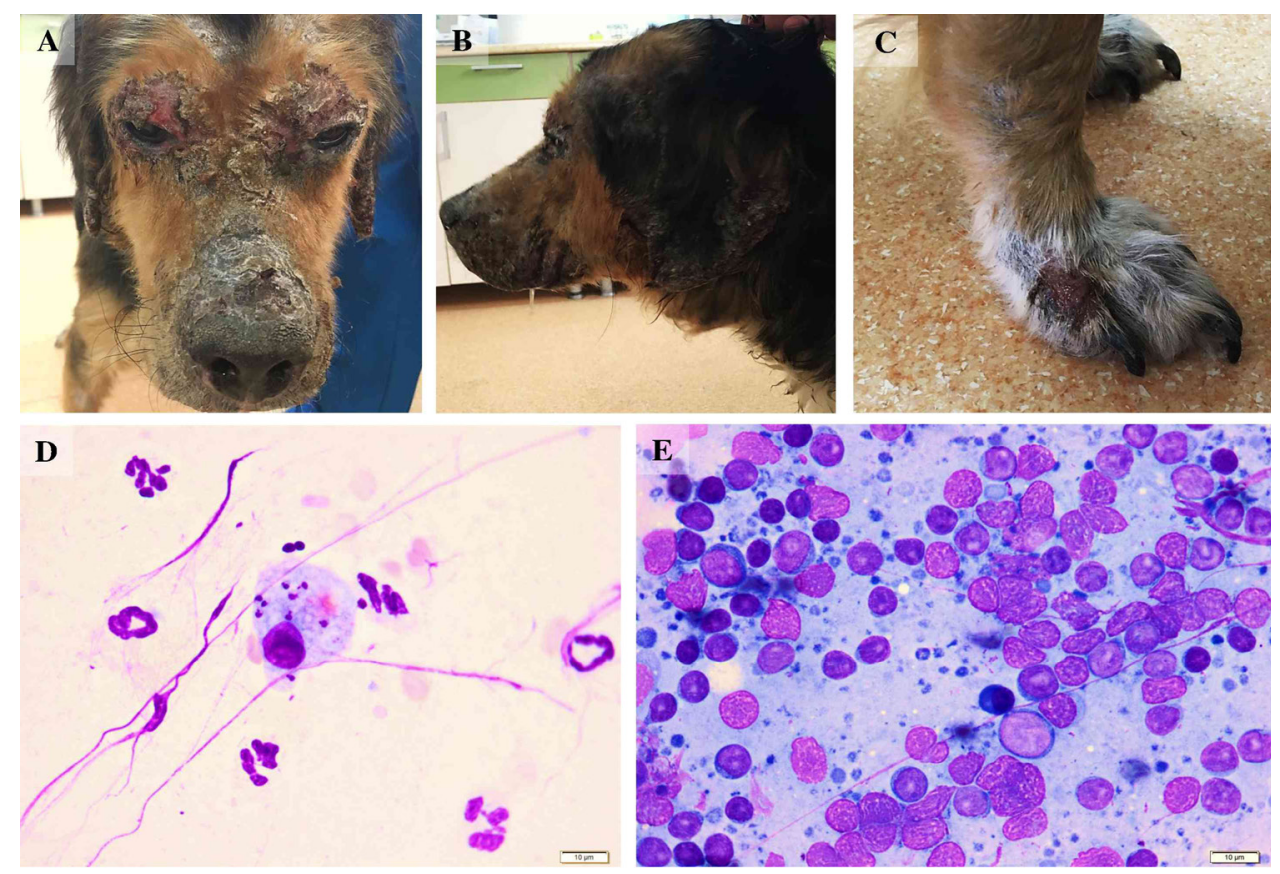

Figure 1. Clinical presentation and histopathological aspects of the L. infantum infection in a dog. A, B: Crusting and scaling dermatitis; C: skin ulcer and onychogryphosis; D: Impression of the internal parts of crusts. Note intracytoplasmatic (macrophage-center) protozoal amastigotes and numerous neutrophils; E: Fine-needle aspirate of lymph node - Mixed population of small lymphocytes and lymphoblast's with an increased number of plasma cells, compatible with a reactive lymph node

performed by car or by plane, and more and more airlines companies accept animals, with accessible taxes. It is estimated that 2.5 million dogs from southern Europe are infected with $L$. infantum (Moreno and Alvar, 2002, Otranto and DantasTorres, 2013). The same region is frequently used by Romanian citizens as a destination for working or relaxation.

Dogs with clinical signs of leishmaniasis (treated or not) and asymptomatic carriers can remain infected by L. infantum, for years and even for their entire life (Moreno and Alvar, 2002, Dantas-Torres, 2007). Less than $50 \%$ of infected dogs may develop a severe disease and clinical signs, while the asymptomatic ones will represent only reservoirs (Alvar et al., 2004, Mohebali et al., 2005). The results obtained in the epidemiological study performed on dogs from Râmnicu Vâlcea by Dumitrache et al., 2016, showed that eight of the tested dogs were positive for L. infantum infection, either by conjunctival swab PCR or blood PCR, but none of these dogs presented clinical signs, compatible with the disease. These asymptomatic individuals should represent a concern from a public health perspective, even in low-risk countries such as Romania. Although
CanL is a disease well known and studied for many years in endemic countries, in Romania, probably because no cases were reported until recently, it is considered by many veterinarians absent and/ or they are not familiar with the clinical signs, diagnosis methods and treatment. Diagnosing CanL can be challenging even for experienced veterinarians from endemic countries, because of the polymorphism of clinical symptoms that may develop, and the variable period of incubation (Dujardin et al., 2008, Farkas et al., 2011, Reiner and Locksley, 1995). This aspect could be confirmed also by the present case. Few months before his arrival in Romania, the dog was referred to a clinic in Italy, with skin disorders that were probably the first signs of CanL. The patient was misdiagnosed. An early and correct diagnostic allows a good prognosis and increase the chances of the therapy. If it is left untreated, Canl is often a fatal disease (Gradoni and Gramiccia, 2004).

In Romania, considering the new epidemiological background and the few information regarding sand fly species and their geographical distribution, cases of CanL, imported and especially autochthonous, are of particularly interest from both public health and veterinary perspec- 
tive. Moreover, these reports as well as the epidemiological studies, could increase the awareness of veterinarians on CanL.

Acknowledgements. This study was supported by the CNCS-UEFISCDI Grant Agency Romania, grant number TE 299/2015.

\section{References}

1. Alvar J, Cañavate C, Molina R, Moreno J, Nieto J (2004). Canine leishmaniasis. Advances in parasitology, 57: 1-88.

2. Antoniou M, Gramiccia M, Molina R, Dvorak V, Volf $P$ (2013). The role of indigenous phlebotomine sandflies and mammals in the spreading of leishmaniasis agents in the Mediterranean region. Euro Surveill, 18: 20540.

3. Dantas-Torres F (2007). The role of dogs as reservoirs of Leishmania parasites, with emphasis on Leishmania (Leishmania) infantum and Leishmania (Viannia) braziliensis. Veterinary parasitology, 149: 139-146.

4. Desjeux P (2001). The increase in risk factors for leishmaniasis worldwide. Trans R Soc Trop Med Hyg, 95: 239-243.

5. Dujardin JC, Campino L, Cañavate C, Dedet JP, Gradoni L, Soteriadou K, Mazeris A, Ozbel Y (2008). Spread of vectorborne diseases and neglect of leishmaniasis, Europe. Emerg Infect Dis, 14: 1013-1018.

6. Dumitrache MO, Nachum-Biala Y, Gilad M, Mircean V, Cazan, CD, Mihalca AD, Baneth G (2016). The quest for canine leishmaniasis in Romania: the presence of an autochthonous focus with subclinical infections in an area where disease occurred. Parasites \& vectors, 9: 297.

7. Farkas R, Tánczos B, Bongiorno G, Maroli M, Dereure J, Ready PD (2011). First surveys to investigate the presence of canine leishmaniasis and its phlebotomine vectors in Hungary. Vector-borne and zoonotic diseases, 11: 823834.

8. Ferroglio E, Maroli M, Gastaldo S, Mignone W, Rossi L (2005). Canine Leishmaniasis, Italy. Emerging Infectious Diseases, 11: 1618-1620.

9. Francino O, Altet L, Sanchez-Robert E, Rodriguez A, Solano-Gallego L, Alberola J, Ferrer L, Sánchez A, Roura X (2006). Advantages of real-time PCR assay for diagnosis and monitoring of canine leishmaniosis. Veterinary parasitology, 137: 214-221.
10. Gogoaşe MG, Teodorescu I, Preda C, Ionescu SC (2013). Two case reports on visceral leishmaniasis diagnosed in Romania. Roum Arch Microbiol Immunol, 72: 49-62.

11. Gradoni L, Gramiccia M (2004). Leishmaniosis. In: S. Linnane \& J. E. Pearson (Eds.) Manual of Standards for Diagnostic Tests and Vaccines. Paris, France: Office International des Epizooties (OIE). Available at: www.oie. int/fr/normes/mmanual/a_00050.htm.

12. Maia C, Cardoso L (2015). Spread of Leishmania infantum in Europe with dog travelling. Veterinary parasitology, 213: 2-11.

13. Maroli M, Feliciangeli MD, Bichaud L, Charrel RN, Gradoni $\mathrm{L}$ (2013). Phlebotomine sandflies and the spreading of leishmaniases and other diseases of public health concern. Medical and Veterinary Entomology, 27: 123-147.

14. Mircean V, Dumitrache MO, Mircean M, Bolfă P, Györke A, Mihalca AD (2014). Autochthonous canine leishmaniasis in Romania: neglected or (re) emerging? Parasites \& vectors, 7(1): 135 .

15. Mohebali M, Hajjaran H, Hamzavi Y, Mobedi I, Arshi S, Zarei Z, Akhoundi B, Manouchehri-Naeini K, Avizeh R, Fakhar M (2005). Epidemiological aspects of canine visceral leishmaniosis in the Islamic Republic of Iran. Vet Parasitol, 129: 243-251.

16. Moreno J, Alvar J (2002). Canine leishmaniasis: epidemiological risk and the experimental model. Trends in parasitology, 18: 399-405.

17. Otranto D, Dantas-Torres F (2013). The prevention of canine leishmaniasis and its impact on public health. Trends in parasitology, 29: 339-345.

18. Ready PD (2010). Leishmaniasis emergence in Europe. Euro surveill, 15: 19505.

19. Reiner SL, Locksley RM (1995). The regulation of immunity to Leishmania major. Ann Rev Immunol, 13: 151-177.

20. Strauss-Ayali D, Jaffe CL, Burshtain O, Gonen L, Baneth G (2004). Polymerase chain reaction using noninvasively obtained samples, for the detection of Leishmania infantum DNA in dogs. J Infect Dis, 189: 1729-1733.

21. World Health Organization (WHO) (2009). Leishmaniasis: background information. A brief history of the disease Available from: www.who.int/leishmaniasis/en/ 